\title{
Furanoterpene fatty acid esters from the Australian marine sponge Coscinoderma mathewsi
}

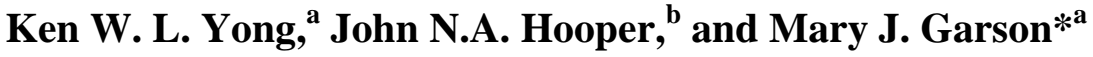 \\ ${ }^{a}$ School of Molecular and Microbial Sciences, The University of Queensland, Brisbane QLD \\ 4072, Australia \\ ${ }^{b}$ Queensland Museum, PO Box 3300, South Brisbane QLD 4100, Australia \\ Email: m.garson@uq.edu.au
}

Dedicated to Professor Torbjorn Norin

\begin{abstract}
Chemical investigation of the sponge Coscinoderma mathewsi collected near Mooloolaba, S.E. Queensland, has led to the isolation of the furanoterpene esters 1a - 1c together with the known furanoterpenes $2-\mathbf{4}$. NMR spectroscopic assignments are provided for the esters, while GC/MS analysis of FAME derivatives $\mathbf{5 a}-\mathbf{5}$ c confirmed the identity of the fatty acid components.
\end{abstract}

Keywords: Sesterterpenoid, fatty acid, FAMES, NMR, sponges, Coscinoderma

\section{Introduction}

Lipid-containing metabolites have been found in both marine microorganisms and in marine invertebrates such as sponges. ${ }^{1,2}$ Fatty acid amide examples include the malyngamide metabolites found in the extracts of cyanobacteria such as Lyngbya spp, ${ }^{3,4}$ while the fatty acid ester derivatives of variabilin, ${ }^{5}$ bengazoles, ${ }^{6,7}$ bengamides ${ }^{7,8}$ and sterols ${ }^{9}$ are typical examples from marine sponges. An ongoing screening program directed at identifying furanoterpenes in sponges collected in S.E. Queensland waters indicated the dictyoceratid sponge Coscinoderma mathewsi as showing evidence of both $\beta$-substituted furanoterpene and lipid metabolites. A detailed chemical study of this sponge has now led to the isolation of the furan fatty acid esters (1a) (1c), together with the known terpenes (2) - (4). This paper reports structural studies on the isolated metabolites, together with a FAME analysis of derivatives (5a) - (5c) that identifies the lipid side chains (Figure 1). 


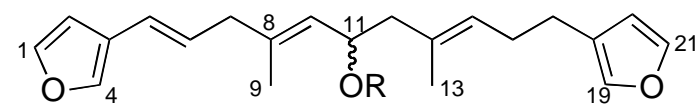

(1a) $\mathrm{R}=\mathrm{CO}\left(\mathrm{CH}_{2}\right)_{11} \mathrm{CHMe}_{2}$

(1b) $\mathrm{R}=\mathrm{CO}\left(\mathrm{CH}_{2}\right)_{10} \mathrm{CHMeCH}_{2} \mathrm{Me}$

(1c) $\mathrm{R}=\mathrm{CO}\left(\mathrm{CH}_{2}\right)_{13} \mathrm{Me}$

(2) $\mathrm{R}=\mathrm{H} ; 11 R$

(3) $\mathrm{R}=\mathrm{Ac}$

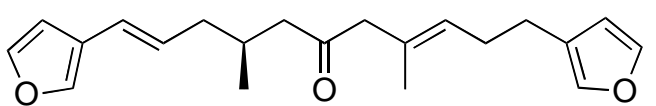

(4)

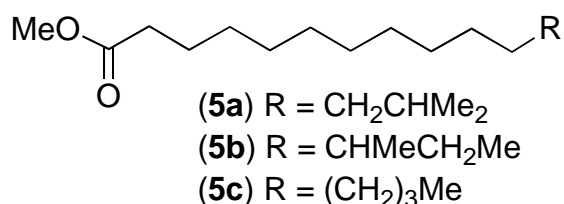

Figure 1. Structures of furanoterpenes isolated from the marine sponge Coscinoderma mathewsi and of some FAME derivatives.

\section{Result and Discussion}

Extraction of the sponge sample with $\mathrm{DCM} / \mathrm{MeOH}$ 1:1 gave a dark-brown extract that was fractionated by silica-gel flash chromatography (hexane/DCM $=>\mathrm{DCM}=>\mathrm{MeOH}$ ), followed by reverse phase $\mathrm{HPLC}$ using a $\mathrm{CH}_{3} \mathrm{CN}: \mathrm{H}_{2} \mathrm{O}$ gradient to give (+)-tetradehydrofurospongin-1 (2), its acetyl derivative (3), ${ }^{10}$ and (-)-untenospongin C (4), ${ }^{11}$ all identified by comparison with literature data. During the investigation of these compounds, a less polar column fraction attracted attention since the ${ }^{1} \mathrm{H}$ NMR spectrum resembled that of the acetyl derivative of tetradehydrofurospongin-1, showing a multiplet signal at $\delta_{\mathrm{H}} 5.63$. similar in appearance to the $\mathrm{H}$ 11 signal for the acetyl derivative of tetradehydrofurospongin-1. However there was no corresponding acetyl signal present at $\delta_{\mathrm{H}}$ 1.97. Instead there were diagnostic terminal methyl signals in the region $\delta_{\mathrm{H}} 0.84-0.87$ and a broad signal for a methylene envelope at approx $\delta_{\mathrm{H}}$ 1.20 that suggested fatty acid ester substitution at the $\mathrm{C}-11$ position of the terpene skeleton. The fraction was further purified through RP-HPLC using a solvent gradient from $80 \% \mathrm{CH}_{3} \mathrm{CN} / \mathrm{H}_{2} \mathrm{O}$ to $100 \% \mathrm{CH}_{3} \mathrm{CN}$ and gave eight fractions $\mathrm{SF} 1-\mathrm{SF} 8$, each of which was examined by proton NMR spectroscopy. Each of the fractions contained the H-11 signal diagnostic for an ester substituent however there were differences for the upfield methyl and methylene signals that hinted at the presence of different fatty acids in the eight fractions. Further evidence for the presence of a fatty ester side chain was the carbonyl signal between 172.5 to $173.0 \mathrm{ppm}$ observed in the ${ }^{13} \mathrm{C}$ NMR spectrum in all eight fractions. Typically the three bond coupling from a oxymethine proton to an adjacent ester functionality ( $\mathrm{H}-\mathrm{C}-\mathrm{O}-\mathrm{CO}-\mathrm{R})$ is about $2.7 \mathrm{~Hz}{ }^{12}$ When a geHMBC experiment optimised for a long range $J_{\mathrm{C}, \mathrm{H}}$ of $4 \mathrm{~Hz}$ was run on fraction F5, a correlation from the proton at $\delta_{\mathrm{H} .} 5.62(\mathrm{H}-11)$ to the ester carbonyl at $173.0 \mathrm{ppm}\left(\mathrm{C}-1^{\prime}\right.$ ') was detected. Other correlations to the ester carbonyl were also observed from the fatty acid ester signals at $\delta_{\mathrm{H}} 2.21$ ( $\mathrm{H}-2^{\prime}$ ) and $\delta_{\mathrm{H}} 1.56$ (thus identified as $\mathrm{H}-3$ ').

The fatty acid substituents present in fraction SF5 were predominantly branched chain fatty

acids by ${ }^{1} \mathrm{H}$ NMR since, in addition to the signals for the parent furanoterpene skeleton that were present, the ${ }^{1} \mathrm{H}$ NMR of the major component showed methyl signals at $\delta_{\mathrm{H}} 0.84(6 \mathrm{H}, \mathrm{d}, \mathrm{H}-14$ ' \& 
H-15') that were diagnostic for a terminal iso- branched chain. 1D proton decoupling and TOCSY experiments were conducted on this sample to identify additional ${ }^{1} \mathrm{H}$ NMR signals. Irradiation of the $\mathrm{H}-14^{\prime} / \mathrm{H}-15^{\prime}$ ' signal identified a signal at $\delta_{\mathrm{H}} 1.49$ as $\mathrm{H}-13$ ', while irradiation of $\mathrm{H}-2^{\prime}$ at $\delta 2.21(2 \mathrm{H}, \mathrm{t})$ led to the assignment of $\mathrm{H}-3^{\prime}$ at $\delta_{\mathrm{H}} 1.56$ and also to some of the overlapping methylene signals $\left(\delta_{\mathrm{H}_{\mathrm{H}}} 1.22\right.$ - 1.32) which extended to the iso-branched terminus. These data were consistent with structure 1a, however it was apparent that the sample also contained smaller amounts of other furan fatty acid esters. A full diagnosis of the fatty acid side chains in these other components was not possible by ${ }^{1} \mathrm{H}$ NMR for two reasons: firstly, there was extensive signal overlap for the upfield methylene protons; and secondly, since the methylene region could not be integrated accurately, it was not possible to determine the chain length of the fatty acids. A GC/MS analysis of this fraction revealed components containing $\mathrm{m} / \mathrm{z} 550$ and $\mathrm{m} / \mathrm{z}$ 578 which corresponded to derivatives of tetradehydrofurospongin-1 containing $\mathrm{C} 15$ and $\mathrm{C} 17$ fatty acyl side chains respectively. A prominent ion at $\mathrm{m} / \mathrm{z} 355$ apparent in each spectrum could possibly be related to a McLafferty-type rearrangement (producing $\mathrm{m} / \mathrm{z}$ 368) and loss of a methyl group.

To confirm the component fatty acids, fraction SF5 was treated with $1.5 \mathrm{M} \mathrm{HCl}$ in methanol, and the resulting mixture of fatty acid methyl esters (FAME) analyzed by GC/MS. The major component (5a) eluted at $22.2 \mathrm{~min}$ and gave a parent ion $\mathrm{m} / \mathrm{z} 256$ with fragmentation at $\mathrm{m} / \mathrm{z} 225$ $\left[\mathrm{M}^{+}-31\right] ; \mathrm{m} / \mathrm{z} 201\left[\mathrm{M}^{+}-55\right] ; \mathrm{m} / \mathrm{z} 200\left[\mathrm{M}^{+}-56\right] ; \mathrm{m} / \mathrm{z} 191\left[\mathrm{M}^{+}-65\right]$ and m/z 74 [McLafferty] which were all diagnostic for a 13-methyltetradecanoate fatty acid ester (iso-15:0) ${ }^{13}$ side chain. A second component (5b) eluted at $22.3 \mathrm{~min}$ also with $\mathrm{m} / \mathrm{z} 256$ gave fragment peaks at $\mathrm{m} / \mathrm{z} 227$ $\left[\mathrm{M}^{+}-29\right] ; \mathrm{m} / \mathrm{z} 196\left[\mathrm{M}^{+}-60\right] ; \mathrm{m} / \mathrm{z} 195\left[\mathrm{M}^{+}-61\right] ; \mathrm{m} / \mathrm{z} 177\left[\mathrm{M}^{+}-79\right]$ and $\mathrm{m} / \mathrm{z} 74$ which were all diagnostic for 12-methyltetradecanoate fatty acid ester (anteiso-15:0) ${ }^{13}$ side chain (1b). Another component (5c) that eluted at 22.6 min was identified as the methyl ester of pentadecanoic acid $(n-\mathrm{C} 15: 0)$. Thus the three major components present from fraction SF5 were furanoterpenes with an iso-15:0 (1a), anteiso-15:0 (1b) and linear 15:0 (1c) side chains. Their FAME derivatives 5a 5c were present in the ratio 21.4: 6.8: 1.0 from integration of the GC/MS trace. Other components present in trace amounts in the FAME sample gave molecular ions at $\mathrm{m} / \mathrm{z} 242,270$, 284 and 298 respectively, suggesting the presence of saturated C14, C16, C17 and C18 fatty acids.

Metabolite (2) has been isolated in both enantiomeric forms. The (+)-isomer was first isolated, from a sponge of the genus Spongia, and named tetradehydrofurospongin- $1,{ }^{14}$ while the (-)-isomer, isolated later from Hippospongia sp. was named untenospongin B. ${ }^{11}$ Our sample of metabolite (2) had a small, positive specific rotation, similar to the reported literature value for the stereoisomer with $11 R$ stereochemistry. ${ }^{10 a, 11}$ Owing to the first report naming the $(+)$-isomer as tetradehydrofurospongin-1, this name is used in preference to untenospongin B. In contrast, the ester mixture (1a) - (1c) and the acetyl derivative (3), that were isolated both showed a small negative value for their specific rotations. Notably, the acetyl derivative 3 showed an $[\alpha]_{D}-5.0(\mathrm{c}$ $\left.0.03, \mathrm{CHCl}_{3}\right)$ in contrast to the literature reported value of +28.9 (c 1.5, $\left.\mathrm{CHCl}_{3}\right)$ for a synthetic sample of the compound that was known to have $11 R$ stereochemistry. ${ }^{10 a}$ Although these data 
may imply $11 S$ stereochemistry for the acylated compounds, the small rotations obtained and the small amount of material available prevent unequivocal assignment of absolute stereochemistry. In particular, there was insufficient material to confirm the absolute configuration at $\mathrm{C}-11$ in compounds $1 \mathbf{a}-\mathbf{1 c}$ by chemical correlation to acetyl derivative 3 . The C-12' configuration of the anteiso-15:0 acid was not evaluated. The configuration of (-)-untenospongin $\mathrm{C}$ has been deduced as $8 S$ by correlation with the known dihydrofurospongin- $2 .{ }^{11}$

The furanosesterterpene chemistry reported for this sample of Coscinoderma mathewsi contrasts with earlier reports of diterpenes, ${ }^{15}$ sesterterpenes, ${ }^{16}$ sulphated sesterterpenes, ${ }^{17}$ and alkaloids ${ }^{18}$ from this sponge genus. Our collection of this sponge from Mooloolaba represents the southernmost known occurrence of the species along the East coast of Australia, and so extends its geographic range. The specimen collected may represent a slight morphological variant compared to specimens from tropical waters, a fact that may explain the difference in metabolite profile.

\section{Experimental Section}

General Procedures. Optical rotations were obtained using a JASCO-P1010 polarimeter. One and two dimensional NMR spectra were acquired using Bruker DRX-500 or Bruker AMX-400 instruments. NMR spectra were obtained in deuterochloroform at room temperature. Samples were internally referenced to $\mathrm{CHCl}_{3}$ at either $\delta_{\mathrm{H}} 7.25$ and $\delta_{\mathrm{C}}$ 77.0. High and low resolution mass measurements were obtained from a Finnigan MAT 900 XL-Trap electrospray (ESI) mass spectrometer with a Finnigan API III electrospray source. Gas chromatography/ mass spectrometry (GC/MS) spectra were recorded on a Shimadzu GCMS-QP5050A gas chromatograph mass spectrometer, carrying a Zebron ZB-5 capillary column $(30 \mathrm{~mL}$ x $0.32 \mathrm{~mm}$ ID x $0.25 \mu \mathrm{m}$ df, $5 \%$ phenyl polysiloxane) with a Shimadzu AOC-20i auto injector. Reverse Phase high performance liquid chromatography (RP HPLC) was performed with an Agilent 1100 series instrument with Water $\mu$ Bondapak semipreparative columns $(10 \mu \mathrm{m}, 7.8 \times 300 \mathrm{~mm})$. Columns were connected to a variable wavelength UV detector and detection at $254 \mathrm{~nm}$. Flow rates were at $1.5 \mathrm{~mL} / \mathrm{min}$.

\section{Biological material}

Specimens of Coscinoderma mathewsi were collected from the Inner Gneerings, a group of shoals off Mooloolaba (Australia), using SCUBA at a depth of 10-15 m on 16 January 2006. Samples were taken back to the laboratory where they were stored at $-20^{\circ} \mathrm{C}$ until extraction. The sponge was a dull grey colour on the exterior with a beige interior. A voucher specimen (QM G324322) is lodged at the Queensland Museum. Photographs of the sponge material are available from the authors. 


\section{Extraction and Isolation of Metabolites}

The specimen of Coscinoderma mathewsi (wet weight $189 \mathrm{~g}$ ) was cut into small pieces and extracted exhaustively with DCM/MeOH (1:1) (3 x $300 \mathrm{~mL})$. The crude extract was concentrated under vacuum to a dark brown oil $(678 \mathrm{mg})$, and subjected to Si flash chromatography using a solvent gradient (hexanes $=>\mathrm{DCM}=>\mathrm{MeOH}$ ). The $\mathrm{CH}_{2} \mathrm{Cl}_{2} / \mathrm{EtOAc}$ (3:2) fraction was further purified by RP HPLC using $\mathrm{CH}_{3} \mathrm{CN} / \mathrm{H}_{2} \mathrm{O}$ (7:3) to afford tetradehydrofurospongin-1 (2) (2.3 mg) eluting at $20.4 \mathrm{~min}$. Next the $\mathrm{CH}_{2} \mathrm{Cl}_{2} /$ EtOAc (4:1) fraction was purified by RP HPLC using $\mathrm{CH}_{3} \mathrm{CN} / \mathrm{H}_{2} \mathrm{O}(8: 2)$ and afforded untenospongin $\mathrm{C}(4)(0.5 \mathrm{mg}, 17.9 \mathrm{~min})$ and the acetyl derivative of tetradehydrofurospongin-1 (3) $(2.0 \mathrm{mg}, 21.4 \mathrm{~min})$. The $100 \% \mathrm{CH}_{2} \mathrm{Cl}_{2}$ fraction was purified by RP HPLC using a solvent gradient of $\mathrm{CH}_{3} \mathrm{CN} / \mathrm{H}_{2} \mathrm{O}(9: 1)$ to $100 \% \mathrm{CH}_{3} \mathrm{CN}$ over 10 min, followed by $100 \% \mathrm{CH}_{3} \mathrm{CN}$ for $30 \mathrm{~min}$ and $100 \% \mathrm{MeOH}$ for another $30 \mathrm{~min}$. This afforded the eight fractions SF1 to SF8.

Tetradehydrofurospongin-1 (2). ${ }^{10}$ Colourless oil; $[\alpha]_{\mathrm{D}}+11.4$ (c 3.10, $\mathrm{CHCl}_{3}$ ), lit. ${ }^{10 \mathrm{a}}+21.8$ (c $0.78, \mathrm{CHCl}_{3}$ ); LREIMS m/z $349[\mathrm{M}+\mathrm{Na}]^{+} ;{ }^{1} \mathrm{H}$ and ${ }^{13} \mathrm{C} \mathrm{NMR}$ - identical with literature data (ref 10a).

Tetradehydrofurospongin-1 acetyl derivative (3). ${ }^{10}$ Colourless oil; $[\alpha]_{\mathrm{D}}-5.0$ (c $\left.0.03, \mathrm{CHCl}_{3}\right)$, lit. ${ }^{10 \mathrm{a}}+28.9$ (c 1.5, $\mathrm{CHCl}_{3}$ ); LREIMS m/z 349 [M+Na-Ac] ; GC-MS $368(<1)$, 149, 95, 81, 69 $(100 \%) ;{ }^{1} \mathrm{H}$ and ${ }^{13} \mathrm{C}$ NMR - identical with literature data (ref $\left.10 \mathrm{~b}\right)$.

Untenospongin $\mathrm{C}(4):^{11}$ colourless oil; $[\alpha]_{\mathrm{D}}-4.6$ (c $0.18, \mathrm{CHCl}_{3}$ ), lit. ${ }^{11}$-9.3 (c 1.0, $\mathrm{CHCl}_{3}$ ); LREIMS $m / z 365[\mathrm{M}+\mathrm{K}]]^{+} ;{ }^{1} \mathrm{H}$ and ${ }^{13} \mathrm{C} \mathrm{NMR}$ - identical with literature data (ref 11).

Tetradehydrofurospongin-1 fatty acid ester derivatives $(1 \mathrm{a}, 1 \mathbf{b}, 1 \mathrm{c})$. $[\alpha]_{\mathrm{D}}$ of mixture -12.5 (c 0.06, $\mathrm{CHCl}_{3}$ ); GC-MS m/z $550[\mathrm{M}]^{+}(<1), 429$ (5), 355 (30), 281 (15), 221 (15), 207 (10), 147 (15), 44 (40), 40 (60); ${ }^{1} \mathrm{H}$ NMR of component $1 \mathrm{a}\left(\mathrm{CDCl}_{3}\right) \delta .7 .34(1 \mathrm{H}$, br s, H-4), 7.31 (1H, br s, H-1), 7.30 (1H, br s, H-21), 7.16 (1H, br s, H-19), 6.48 (1H, br s, H-2), 6.23 (1H, br s, H-20), $6.22(1 \mathrm{H}, \mathrm{d}, J=15 \mathrm{~Hz}, \mathrm{H}-5), 5.84(1 \mathrm{H}, \mathrm{dt}, J=15,7 \mathrm{~Hz}, \mathrm{H}-6), 5.62$ (1H, m, H-11), 5.18 (1H, d, $J$ $=7 \mathrm{~Hz}, \mathrm{H}-15), 5.15$ (1H, d, J= $7 \mathrm{~Hz}, \mathrm{H}-10), 2.80$ (2H, br s, H-7), 2.40 (2H, t, J = $7 \mathrm{~Hz}, \mathrm{H}-17)$, $2.31(1 \mathrm{H}, \mathrm{m}, \mathrm{H}-12 \mathrm{a}), 2.21\left(2 \mathrm{H}, \mathrm{t}, J=7 \mathrm{~Hz}, \mathrm{H}-2^{\prime}\right), 2.20$ (2H, q, $\left.J=7 \mathrm{~Hz}, \mathrm{H}-16\right), 2.13$ (1H, m, H12b), 1.70 (3H, s, H-9), 1.61 (3H, s, H-14), 1.56 (2H, m, H-3'), 1.49 (1H, m, H-13'), 1.32 - 1.22 $\left(16 \mathrm{H}, \mathrm{m}, \mathrm{CH}_{2}\right), 1.13\left(2 \mathrm{H}, \mathrm{m}, \mathrm{H}-12\right.$ '), $0.84\left(6 \mathrm{H}, \mathrm{d}, J=6 \mathrm{~Hz}, \mathrm{H}-14\right.$ ', H-15'); ${ }^{13} \mathrm{C} \mathrm{NMR}$ of component 1a $\left(\mathrm{CDCl}_{3}\right)$ \&. 173.0 (C-1'), 143.2 (C-1), 142.7 (C-21), 139.3 (C-4), 138.7 (C-8), 138.5 (C-19), 131.2 (C-13), 127.2 (C-15), 127.1 (C-6), 124.6 (C-18), 124.2 (C-10), 124.0 (C-3), 121.2 (C-5), 110.8 (C-20), 107.3 (C-2), 69.5 (C-11), 44.7 (C-12), 42.3 (C-7), 39.1 (C-12'), 34.2 (C-2'), 29.7 - 27.4 (8C), 28.2 (C-16), 28.0 (C-13'), 25.0 (C-3'), 24.3 (C-17), 22.7 (C-14' \& C$\left.15^{\prime}\right), 16.8$ (C-9), 16.1 (C-14).

\section{Preparation of fatty acid methyl ester derivatives (FAMEs)}

Furanoterpene fatty acid ester SF5 was treated with $1.5 \mathrm{M}$ of $\mathrm{HCl}$ in $\mathrm{MeOH}(1 \mathrm{~mL})$ in a screwcapped vial and refluxed for 1 hour at $65^{\circ} \mathrm{C}$. The residual liquid was removed by a stream of $\mathrm{N}_{2}$ (g) before addition of $0.5 \mathrm{~mL}$ toluene that was also then removed under a stream of $\mathrm{N}_{2}(\mathrm{~g})$. The crude transmethylated fatty ester was dissolved in $1 \mathrm{~mL}$ of hexane and passed through a short 
silica column ( $0.5 \mathrm{~g}$ silica) using hexane $(10 \mathrm{~mL})$ as a solvent. The eluted FAME was evaporated to dryness prior to GC-MS analysis which revealed (5a) iso-15:0, Rt $22.2 \mathrm{~min}$ ), (5b) (anteiso15:0, Rt $22.3 \mathrm{~min})$ and (5c) (n15:0, Rt $22.6 \mathrm{~min})$ in the ratio 21.4: 6.8: 1.0.

Methyl 13-methyltetradecanoate (iso-15:0) (5a). GC-MS m/z $256[\mathrm{M}]^{+}$(2), 225 (1), 213 (7), 199 (3), 185 (2), 171 (1), 157 (4), 143 (9), 129 (4), 111 (1), 101 (6), 87 (42), 74 (100), 69 (20), 57 (20), 55 (25), 43 (66), 41 (59).

Methyl 12-methyltetradecanoate (anteiso-15:0) (5b). GC-MS m/z $256[\mathrm{M}]^{+}$(1), 225 (2), 213 (4), 199 (14), 185 (1), 177 (1), 157 (2), 143 (9), 129 (4), 115 (4), 101 (4), 87 (46), 74 (100), 57 (35), 43 (61), 41 (69).

Methyl pentadecanoate (n-15:0) (5c). GC-MS m/z 256 [M] $]^{+}$(4), 225 (2), 213 (3), 199 (2), 185 (2), 171 (2), 157 (3), 143 (12), 129 (6), 115 (2), 97 (7), 87 (45), 76 917), 74 (100), 69 (15), 57 (18), 55 (27), 43 (40).

\section{Supplementary Information Available}

Figures S1 - S2. ${ }^{1} \mathrm{H}$ NMR for the fraction containing compounds 1a - 1c and GC-MS data for compounds 5a-5c. Figure S3. A surface photograph of a specimen of Coscinoderma mathewsi.

\section{Acknowledgements}

We thank L. Lambert (Centre for Magnetic Resonance, UQ), G. MacFarlane of the School of Molecular and Microbial Science, UQ, for spectroscopic assistance, Prof. R. Capon, Institute for Molecular Bioscience, UQ, for assistance with the measurements of $[\alpha]_{\mathrm{D}}$ values, and Drs $\mathrm{M}$. Cryle and J. De Voss for assistance with GC/MS measurements. ScubaWorld Mooloolaba assisted with access to dive sites for the sample collection (carried out under permit from the Department of Primary Industries and Fisheries, Queensland).

\section{References}

1. Faulkner, D. J. Nat. Prod. Rep. 2002, 19, 1-48, and previous articles in this review series.

2. Blunt, J. W.; Copp, B. R.; Munro, M. H. G.; Northcote, P. T.; Prinsep, M. R. Nat. Prod. Rep. 2006, 23, 26-78, and previous articles in this review series.

3. Gerwick, W. H.; Tan, L. T.; Sitachitta, N. In Cordell, G. A., Ed.; The Alkaloids: Chemistry and Biology, Vol. 57. Academic Press: San Diego, 2001; pp 75-184.

4. Tan, L. T. Phytochemistry 2007, 68, 954.

5. (a) Martínez, A.; Duque, C.; Hara, N.; Fujimoto, Y. Nat. Prod. Lett. 1995, 6, 281. (b) Martínez, A.; Duque, C.; Fujimoto, Y. Lipids 1997, 32, 565. 
6. (a) Adamczeski, M.; Quiñoà, E.; Crews, P. J. Am. Chem. Soc. 1988, 110, 1598. (b) Rodríguez, J.; Nieto, R. M.; Crews, P. J. Nat. Prod. 1993, 56, 2034. (c) Rudi, A.; Kashman, Y.; Benayahu, Y.; Schleyer, M. J. Nat. Prod. 1994, 57, 829.

7. (a) Adamczeski, M.; Quiñoà, E.; Crews, P. J. Am. Chem. Soc. 1989, 111, 647. (b) Fernandez, R.; Dherbomez, M.; Letourneux, Y.; Nabil, M.; Verbist, J. F.; Biard, J. F. J. Nat. Prod. 1999, 62, 678. (c) Groweiss, A.; Newcomer, J. J.; O’Keefe, B. R.; Blackman, A.; Boyd, M. R. J. Nat. Prod. 1999, 62, 1691.

8. (a) Quiñoà, E.; Adamczeski, M.; Crews, P.; Bakus, G. J. J. Org. Chem. 1986, 51, 4494. (b) Adamczeski, M.; Quiñoà, E.; Crews, P. J. Org. Chem. 1990, 55, 240. (c) D'Auria, M. V.; Giannini, C.; Minale, L.; Zampella, A.; Debitus, C.; Frostin, M. J. Nat. Prod. 1997, 60, 814. (d) Thale, Z.; Kinder, F. R.; Bair, K. W.; Bontempo, J.; Czuchta, A. M.; Versace, R. W.; Phillips, P. E.; Sanders, M. L.; Wattanasin, S.; Crews, P. J. Org. Chem. 2001, 66, 1733.

9. Duque, C.; Cepeda, N.; Martínez, A. Lipids 1993, 28, 767.

10. (a) Fontana, A; Albarella, L.; Scognamiglio, G.; Uriz, M. Cimino, G. J. Nat. Prod. 1996, 59, 869. (b) Cimino, G.; De Rosa, S.; De Stefano, S.; Morrone, R.; Sodano, G. Tetrahedron 1985, 41, 1093.

11. Kobayashi, J.; Shinonaga, H.; Shigemori, H.; Sasaki, T. Chem. Pharm. Bull. 1993, 41, 381.

12. Kalinowski, H. O.; Berger, S.; Braun, S. Carbon-13 NMR Spectroscopy; John Wiley and Sons: Chichester, 1988.

13. Apon, J. M. B.; Nicolaides, N. J. Chromatogr. Sci. 1975, 13, 467.

14. Kaslauskas, R.; Murphy, P. T.; Quinn, R. J.; Wells, R. J. Tetrahedron Lett. 1976, 1331.

15. Hyosu, M.; Kimura, J. J. Nat. Prod. 2000, 63, 422.

16. (a) Alea, G. V.; Carroll, A. R.; Bowden, B. F. Aust. J. Chem. 1994, 47, 191. (b) Kimura, J.; Hyosu, M. Chem. Lett. 1999, 61.

17. (a) Fu, X.; Ferreira, M. L. G.; Schmitz, F. J.; Kelly, M. J. Nat. Prod. 1999, 62, 1190. (b) Kimura, J.; Ishizuka, E.; Nakao, Y.; Yoshida, W. Y.; Scheuer, P. J.; Kelly-Borges, M. J. Nat. Prod. 1998, 61, 248 (and see p. 862). (c) Loukaci, A.; Le Saout, I.; Samadi, M.; Leclerc, S.; Damiens, E.; Meijer, L.; Debitus, C.; Guyot, M. Biol. Med. Chem. 2001, 9, 3049.

18. Bokesch, H. R.; Pannell, L. K.; McKee, T. C.; Boyd, M. R. Tetrahedron Lett. 2000, 41, 6305. 